\title{
Single Phase Convective Heat Transfer Passive Enhancement: Techniques, Mechanisms, Performance Comparisons and Applications
}

\author{
Poh Seng (PS) Lee, PhD, ASME Fellow \\ Associate Professor, Department of Mechanical Engineering \\ Deputy Executive Director, Energy Studies Institute (ESI) \\ Director, Singapore Energy Centre (SgEC) \\ Director, Centre for Energy Research \& Technology (CERT) \\ Programme Director, Cooling Energy Science \& Technology Singapore (CoolestSG) National Consortium \\ National University of Singapore, Singapore
}

\begin{abstract}
In this keynote lecture an overview of single phase convective heat transfer passive enhancement techniques and their underlying mechanisms is provided. Then detailed analyses of the hydraulic and thermal performances of selected works conducted by the speaker's group related to thermal boundary layer redevelopment, secondary flow generation and waviness are provided to demonstrate the effectiveness of these approaches. Finally, the application of these techniques for solving various practical cooling problems ranging for direct chip liquid cooling of servers to passive displacement cooling of buildings is discussed lic performance comparisons of the enhanced structures.
\end{abstract}

